\title{
Luis Antonio PAULINO*
}

\section{O dilema da ALCA}

"Nossas dúvidas nos traem e fazem muitas vezes com que se perca o bem que poderia ser nosso por receio de arriscar".

Shakespeare.

(Medida por medida, ato 4, cenal).

\section{Resumo}

A adesão à Área de Livre Comércio das Américas - ALCA - tornou-se um dilema para o Brasil, uma verdadeira encruzilhada histórica. A decisão que for tomada será um daqueles eventos cruciais para o futuro da nação. $\mathrm{O}$ que está em jogo não é apenas a nossa balança comercial mas o próprio futuro da economia brasileira. Ao decidirmos se aceitamos ou não o acordo e principalmente suas condições finais, no caso de uma eventual aceitação, estaremos definindo a estrutura em torno da qual a economia brasileira evoluirá nas próximas décadas, ou seja, como será o Brasil em meados do século XXI.

\section{Abstract}

The adhesion to the America' S Free Commerce Area-ALCA - has become a dilemma to Brazil, a real historical crossroads. The decision, which was taken it will be one of those crucial events to the nation future. What is at stake is not only our commercial balance, but the Brazilian economy. Own future. By deciding whether or not to accept the accord and principally their final conditions, in the case of na eventual acceptance, it will be defining the structure around the Brazilian economy will evolve the ongoing decades, that is, as Brazil will be in the meadows of XXI century.
O dilema central diante do qual o país está colocado é o seguinte: aderir a uma área de livre comércio carregada, nas palavras de Hélio Jaguaribe, de "falaciosas reciprocidades" e correr o risco de transformar o país numa província do Império americano, sem projeto próprio de desenvolvimento, governado internacionalmente ou, então, dizer não à ALCA e correr o risco de cair num limbo comercial que o representante comercial dos EUA, Robert Zoellick, definiu de forma provocativa, em entrevista ao jornal "The Miami Herald", como "fazer comércio mais ao sul, com a Antártida".

Como nenhuma das duas possibilidades acima interessam ao Brasil, a questão central colocada hoje é formular alternativas que nos permitam fugir desse dilema, seja obtendo um acordo favorável aos interesses nacionais, seja rejeitando o acordo sem isolar-se dos demais países da América do Sul que os Estados Unidos, espertamente, tentam seduzir oferecendo vantagens diferenciadas.

Uma alternativa óbvia seria convencer os Estados Unidos a mudarem os termos de sua proposta naqueles pontos considerados inaceitáveis ou insatisfatórios para o Brasil; a outra, caso a primeira não funcione, seria conseguir que os países da América do Sul, os do Mercosul em particular, rejeitem a proposta norte-americana e partam para a concretização de outros acordos de livre comércio, particularmente com a Índia, China e Rússia, que compensem as eventuais perdas comerciais de curto prazo decorrentes da não concretização da ALCA ou da criação de uma ALCA sem o Mercosul.

Para que possamos aquilatar a viabilidade de cada uma dessas alternativas, vamos analisar nos

\footnotetext{
* Doutor em Ciências Econômicas - UNICAMP. Mestre em Administração Pública - FGV/SP. Professor dos cursos de Ciências Econômicas e Comércio Exterior das Faculdades Integradas "Campos Salles".

' CARVAlHO, Marco Antônio de. O Brasil não pode ser província. Gazeta Mercantil, São Paulo, 7 mar. 2002.

${ }^{2}$ SOTERO, Paulo. Alca não é anexação, afirma Zoellick. O Estado de São Paulo, São Paulo, 15 jan. 2002.
} 
pontos seguintes a estratégia dos dois países que têm maior peso no processo de constituição da ALCA: Estados Unidos e Brasil. Antes, porém, vamos atualizar o cenário em torno do qual as discussões atualmente se desenvolvem, uma vez que o futuro das negociações em curso estão condicionadas pelo que já foi acertado no passado recente, seja quanto ao escopo seja quanto ao cronograma de implantação do acordo.

\section{A agenda da ALCA}

Por iniciativa do então presidente dos Estados Unidos, Bill Clinton, realizou-se em Miami, em dezembro de 1994, a Primeira Cúpula das Américas, da qual participaram presidentes e chefes de Estado de todos os países do hemisfério, com exceção de Cuba. Nesse encontro foi estabelecido um plano de ação visando estabelecer uma Área de Livre Comércio das Américas (ALCA) para o ano de 2005.

A ALCA (Área de Livre Comércio das Américas) é uma proposta de integração comercial que, se concluída, abrangerá todos os países das Américas, exceto Cuba, num total de 34 países membros. Uma vez estabelecida, a ALCA reunirá numa mesma área de livre comércio cerca de 874 milhões de pessoas, uma corrente de comércio de quase US\$ 3 trilhões e uma produção econômica conjunta de US\$ 11 trilhões.

Os países-membros terão, entre si, preferências tarifárias, ou seja, eliminarão ou reduzirão substancialmente as tarifas alfandegárias para o comércio de bens e serviços realizado entre si. $\mathrm{O}$ objetivo, portanto, é que as tarifas intrabloco sejam reduzidas até que fiquem zeradas.

Embora a questão da liberalização do comércio de mercadorias entre os países-membros seja a questão mais candente do acordo e a que mais tem chamado a atenção da mídia e da opinião pública em geral, a proposta da ALCA não se reduz a isso; foram formados nove grupos de negociação para tratar de temas específicos que deverão ser contemplados no acordo.
Os temas que estão sendo negociados nesses grupos são os seguintes:

- Acesso a mercados;

- Investimentos;

- Serviços;

- Compras do setor público;

- Solução de controvérsias;

- Agricultura;

- Direitos de propriedade intelectual;

- Subsídios/antidumping/direitos compensatórios;

- Política de competição.

Muito embora fuja ao escopo deste artigo o detalhamento do teor das discussões que estão se dando no âmbito de cada grupo de negociação, é importante que se diga que são temas da maior importância e que, em certo sentido, poderão afetar as economias dos países envolvidos de maneira mais profunda que a questão das trocas comerciais.

Há um grande temor, por exemplo, que as regras sobre investimentos sejam um cópia do capítulo 11 do Nafta (acordo de livre comércio entre os EUA, México e Canadá) que transfere para tribunais externos as disputas entre investidores e governos, dificultando a proteção dos produtores locais e praticamente impedindo a aplicação das leis nacionais até mesmo no campo ambiental. A empresa norte-americana Bechtel, por exemplo, está processando a Bolívia no tribunal arbitral do Banco Mundial e reclama a indenização de US\$ 25 milhões pelo cancelamento, em 2000 , da concessão do serviço de água em Cochabamba, depois de protestos contra um aumento de tarifas que provocaram nove mortes e levaram o governo a decretar estado de sítio ${ }^{3}$. Há outros casos de empresas americanas que processaram os governos do Canadá e do México em tribunais externos no âmbito do Nafta, venceram as demandas e obrigaram os governos locais a pagar indenizações milionárias ou a modificar locais que supostamente prejudicavam os interesses dessas empresas. Questões desse tipo têm tudo a ver com o que está sendo discutido na ALCA e preocupam mais que a mera liberação dos fluxos de comércio.

${ }^{3}$ ANTUNES, Cláudia. O que importa na Alca. Folha de S. Paulo. São Paulo, 22 jan.2003. 
No caso específico do comércio de bens, pelas regras da ALCA já aprovadas pelos grupos de negociação haverá quatro prazos para o livre comércio. Para alguns produtos, a alíquota de importação será reduzida a zero imediatamente a partir da formalização do acordo, previsto para 2005. O segundo prazo inclui produtos em que a alíquota será reduzida gradualmente em cinco anos. Um terceiro grupo de produtos terá a alíquota reduzida gradualmente em dez anos. Há ainda o quarto grupo, no qual as alíquotas de importação levarão mais de dez anos para serem zeradas ${ }^{4}$.

Até o final de 2002, foram realizadas seis reuniões ministeriais de comércio em âmbito hemisférico para definir os termos gerais da ALCA. $\mathrm{Na}$ última delas, realizada em Quito, no Equador, o Brasil assumiu, junto com os EUA, a co-presidência da comissão para formação da ALCA e deverá exercê-la até o final das negociações.

O calendário das negociações, para 2003, previa a apresentação de ofertas (o que os países oferecem aos parceiros para conseguir fechar o acordo) até 15 de fevereiro. $\mathrm{O}$ Brasil, junto com o Mercosul, resolveu atrasar a entrega de propostas para compras do setor público, investimentos e serviços. Entre 16 de fevereiro de 2003 e 15 de junho de 2003, cada país, diante das ofertas dos parceiros, deverá fazer pedidos de melhorias de ofertas e a partir de 15 de junho inicia-se o processo de apresentação de ofertas revisadas. Em 2004 está prevista uma nova reunião ministerial em Brasília, para eventualmente concluir as negociações. Em 2005 será realizada, na Argentina, a IV Cúpula das Américas, depois do término das negociações e, o mais tardar em 1 은 de janeiro de 2006, a ALCA deverá entrar em vigor, iniciando-se o processo de desagravação tarifária entre os 34 países que participam das negociações do bloco.

\section{A estratégia americana: o que os EUA querem com a ALCA}

Os Estados Unidos são de longe, entre os 34 países que estão negociando o acordo, o país com maior poder e capacidade de intervir no rumo das negociações; o tamanho de seu mercado, a força de sua economia e a hegemonia política e militar que exercem mundialmente fazem deles um parceiro absolutamente desproporcional nesse jogo. E esse talvez seja o maior problema: como negociar em condições de igualdade com um parceiro tão desigual.

Conforme se observa na tabela abaixo, os Estados Unidos respondem, isoladamente, por cerca de $80 \%$ de toda a produção de bens e serviços e por $60 \%$ da corrente de comércio dos 34 países do bloco.

\begin{tabular}{|l|c|c|c|c|}
\hline País/bloco & PIB (em US\$ bi) & População (em milhões) & Exportações (em US\$ bi) & Importações (em US\$ bi) \\
\hline EUA & 8.700 & 272 & 642 & 1.059 \\
\hline Brasil & 557 & 168 & 48 & 51 \\
\hline Mercosul (4) & 868 & 213 & 74 & 82 \\
\hline Demais países (27) & 447 & 234 & 83 & 88 \\
\hline Nafta & 9.787 & 400 & 1.017 & 1.420 \\
\hline ALCA & 11.102 & 847 & 117 & 1.590 \\
\hline
\end{tabular}

Cientes de que o tamanho de seu mercado e a voracidade de seus consumidores representam um grande atrativo para qualquer país que pretenda expandir sua atividade exportadora, os EUA estão conduzindo as negociações de forma extremamente dura e utilizando esse trunfo como um verdadeiro pé de cabra para abrir à força os mercados externos para os produtores norte- americanos, além de tentar impor, nos demais temas em negociação, condições privilegiadas para a atuação e expansão dos mercados das empresas norte-americanas. Além disso, o Congresso americano, para aprovar o mandato negociador para o governo Bush através do "Bipartisan Trade Promotion Authority Act" (antigo Fast Track), sem o qual o governo americano não tem como fechar

${ }^{4}$ VERÍSSIMO, Renata. País prepara lista comum para a Alca. O Estado de São Paulo, São Paulo, 23 jan. 2003. 
acordos sem garantir que os mesmos sejam posteriormente mutilados pelo Congresso, impôs toda sorte de restrições às concessões que o governo poderá vir a fazer no processo de negociação.

Conforme especifica o referido documento:

um dos principais objetivos de negociação é preservar a capacidade dos Estados Unidos de aplicar rigorosamente as suas leis comerciais, inclusive as leis antidumping, de direitos compensatórios e de salvaguardas, e evitar acordos que diminuam a efetividade de restrições nacionais e internacionais ao comércio injusto, especialmente dumping e subsídios $(. .)^{5}$

De todos os mecanismos que o governo norteamericano está utilizando para impor sua vontade na questão da ALCA, talvez o mais nocivo aos interesses do Brasil seja o tratamento diferenciado que está propondo a diferentes grupos de países do bloco em termos de acesso ao mercado norteamericano. Na reunião ministerial de Quito, realizada em outubro de 2002, os representantes brasileiros opuseram-se firmemente à proposta americana de fazer ofertas diferenciadas de acesso ao mercado norte-americano segundo o "grau de desenvolvimento" de cada país do bloco, pois era evidente que tal estratégia não tinha nada de humanitária; visava apenas a enfraquecer a posição do Mercosul e do Brasil em particular, ao tentar atrair para si o apoio das economias menores do continente, uma vez que poderiam atender facilmente suas demandas com um custo mínimo.

Em mais uma demonstração da forma autoritária com que pretendem conduzir as discussões, não levaram em conta as objeções dos negociadores brasileiros e no "esboço" da oferta dos Estados Unidos para a ALCA, apresentado no dia 11 de fevereiro de 2003, romperam uma regra básica dôs tratados de comércio realizados sob o âmbito do antigo Gatt e agora da OMC que é o princípio de nação mais favorecida, segundo o qual a melhor oferta realizada a um dos parceiros comerciais tem necessariamente de ser oferecida aos demais parceiros. Ao invés de apresentarem um conjunto de propostas iguais para todos os futuros parceiros da ALCA, estão propondo ofertas diferentes para cada grupo de países. Sob a justificativa de estar permitindo o acesso mais rápido ao mercado norte-americano para aqueles países ou grupo de países com menor desenvolvimento relativo, os Estados Unidos estão tentando semear a cizânia entre os parceiros do bloco visando isolar o Mercosul, principalmente o Brasil, cujas demandas de abertura do mercado norte-americano são maiores e mais difíceis de serem atendidas sem confrontar-se com os interesses de poderosos lobbies de setores pouco competitivos da economia norte-americana que seriam seriamente afetados, caso os produtores brasileiros tivessem livre acesso ao seu mercado. Além disso, a idéia de discriminação entre possíveis parceiros na transição rumo à ALCA coloca os Estados Unidos no centro do processo de negociação, configurando um modelo de negociação conhecido como hub and spoke (centro e raios, como numa roda de bicicleta) com os Estados Unidos, naturalmente, ocupando o centro.

O objetivo dos EUA é colocar o Brasil no córner. Como lembra Sardenberg:

Se o Brasil permanecer isolado, enquanto os demais países se entendem com os EUA, é prejuizo certo. Cerca de $25 \%$ das exportações brasileiras vão para os EUA. Outro tanto, na verdade um pouco mais, vai para os demais países das Américas. Ou seja, o risco é o Brasil ficar de fora num acordo que envolve países que são o destino de mais de $50 \%$ das nossas exportações

A essência da estratégia americana é, portanto, colocar-se no centro das negociações e conduzir o processo da ALCA como mera extensão do Nafta (Acordo de livre comércio entre os Estados Unidos, Canadá e México que está completando dez anos de funcionamento) visando,

${ }^{5}$ BATISTA JR., Paulo Nogueira. Os EUA e a Alca. Folha de São Paulo, São Paulo, 20 fev. 2003.

${ }^{6}$ SANDENBERG, C.A. A globalização pára. Na vez dos pobres. O Estado de São Paulo, São Paulo, 17 fev. 2003. 
sobretudo, ampliar o acesso dos produtores americanos aos mercados dos demais parceiros do bloco, sem fazer concessões substantivas em termos de acesso ao seu próprio mercado. Partem do princípio de que a economia norte-americana já é relativamente aberta, que tem experimentado um déficit significativo em sua balança comercial com o resto do mundo e não haveria, portanto, necessidade de fazer maiores concessões.

O problema é que para países como o Brasil que são altamente competitivos exatamente nos setores nos quais os EUA mantêm tarifas de importação elevadas e, principalmente, todo um arsenal de barreiras não tarifárias que inviabilizam as exportações de inúmeros produtos para aquele país, o fato das tarifas médias de importação dos Estados Unidos serem de 2\% não significa nada.

Os produtos agrícolas, frutas, vegetais e carnes do Brasil são impedidos de entrar no mercado americano por barreiras sanitárias na maioria das vezes injustificadas; as nossas exportações de aço e ligas de ferro são as maiores vítimas de medidas antidumping e direitos compensatórios; nossos calçados e roupas têm que enfrentar tarifas proibitivas e cotas tão restritas que inviabilizam seu acesso ao mercado americano.

Recente estudo da Embaixada Brasileira em Washington constatou que a tarifa média aplicada pelos EUA aos quinze principais produtos brasileiros de exportação alcançava a média de $45,6 \%$; em contraste, a tarifa média brasileira para as 15 maiores exportações norteamericanas para o nosso mercado era de $14,3 \%$.

Como constatou Ricupero, em artigo recente:

...certas tarifas americanas, em especial as incidentes sobre exportações que excedam quotas, são de tal maneira elevadas que eliminam qualquer possibilidade de exportação. Esse é, por exemplo, o caso do açúcar ( $236 \%$ extra-cota), tabaco ( $350 \%$ extra-cota), etanol (2,5\% mais US\$ 0,52 por galão), suco de laranja
(US\$ 0,785 por litro). Ademais, diversos estudos indicam que cerca de $60 \%$ de todos os produtos exportados pelo Brasil para os EUA são afetados, de uma maneira ou de outra, por barreiras tarifárias e não tarifárias, alguns tendo desaparecido completamente do mercado americano após a imposição de sanções, outros tendo de enfrentar tarifas altíssimas como certos têxteis (38\% ad valorem, mais US\$ 0,485 por quilo).?

Além dessas restrições de acesso ao mercado norte-americano, os produtos agrícolas brasileiros enfrentam a concorrência desleal dos produtos americanos em terceiros mercados, devido aos subsídios que o governo dos Estados Unidos oferece à produção e à exportação de seus produtores agrícolas. Segundo estudo da Embaixada do Brasil em Washington ${ }^{8}$, o produtor americano de soja recebe subsídios e pagamentos emergenciais, que causaram perdas de US $\$ 800$ a US $\$ 1$ bilhão por ano aos produtores brasileiros; no caso do algodão, os subsídios na safra de 2001/2002 foram de US\$ 2,4 bilhões e estão deprimindo preços internacionais, com danos à economia brasileira de US\$ 638 milhões.

Os principais pontos da proposta americana para a ALCA apresentados em 11 de fevereiro de 2003 são os seguintes:

- Cerca de $65 \%$ das importações de bens duráveis e de consumo do hemisfério (não cobertas pelo Nafta) ficariam isentas imediatamente de tarifas sob a ALCA; os Estados Unidos propõem o fim das tarifas para produtos industriais e de consumo em 2015.

- Importações de têxteis e confecções dos países da ALCA ficariam livres de tarifas em 5 anos, desde que medidas recíprocas também fossem implementadas.

- Eliminação imediata de tarifas recíprocas nos setores.

Quanto às questões consideradas centrais pelos negociadores brasileiros para viabilização do

\footnotetext{
${ }^{7}$ RICUPERO, Rubens. Os Estados Unidos e o comércio mundial: protecionistas ou campeões do livre-comércio. Estudos Avançados 46. São Paulo: Instituto de Estudos Avançados da Universidade de São Paulo. 2002.

${ }^{8}$ BRASIL, Embaixada do Brasil em Washington, D.C. Barreiras aos produtos e serviços brasileiros, out. 2002.
} 
acordo, ou seja, a questão agrícola e o uso abusivo de medidas anti-dumping, a proposta norteamericana não faz menção.

$\mathrm{Na}$ verdade, os EUA já manifestaram a opinião que tanto uma questão quanto a outra deveriam ser tratadas no âmbito da $\mathrm{OMC}$ e não da ALCA. Alegam, no caso da agricultura, que não teriam como eliminar os subsídios milionários oferecidos aos seus produtores, caso a União Européia não fizesse o mesmo, pois perderiam competitividade em terceiros mercados; no caso das medidas anti-dumping, a justificativa apresentada baseia-se no fato de que o mandato negociador aprovado pelo Congresso norteamericano (o TPA) exige explicitamente que um eventual acordo não afete a capacidade do governo americano aplicar suas próprias leis de comércio que são escandalosamente favoráveis ao uso abusivo das medidas anti-dumping como instrumento de defesa dos produtores americanos. Recentemente houve mudança nessa legislação, aprovada no apagar das luzes do governo Clinton, conhecida como Lei HelmesBurton, estabelecendo inclusive que os recursos arrecadados através de aplicação de sobretaxas decorrentes de medidas anti-dumping sejam destinados às empresas norte-americanas reclamantes. Não poderia haver maior estímulo para o recurso abusivo a esse tipo de medida do que uma lei desse jaez.

Estranhamente, no entanto, ao mesmo tempo que privilegiam o foro da OMC para tratar da questão agrícola, nas outras áreas de negociação, como investimentos, propriedade intelectual, compras governamentais etc. consideram a ALCA como o foro mais adequado para discutir e propõem, inclusive, novos balizamentos nesses temas que sejam, na linguagem cifrada do comércio internacional, OMC-Plus, ou seja, que ultrapassem as disciplinas estabelecidas pela OMC. É o caso típico de dois pesos e duas medidas.
Muito embora, diante dos sinais de que o governo brasileiro pretende endurecer o jogo no processo de negociação, os negociadores americanos tenham abrandado em parte seu discurso arrogante, dizendo que tudo está na mesa de negociação", que não há nada inegociável, na prática não se mostram dispostos a arredar pé de suas posições e continuam a tratar o Brasil, na melhor das hipóteses, como coadjuvante, cujas propostas serão levadas em conta, se, e somente, coincidirem com a deles.

\section{A estratégia brasileira: o que o Brasil espera da ALCA}

Estudos realizados por universidades e organizações empresariais brasileiras estimam que, caso a proposta da ALCA, nos termos propostos pelos EUA, for aprovada, haverá prejuízos para o Brasil da ordem de US\$ 1 bilhão por ano nas relações de troca entre os dois países, além das possíveis perdas em terceiros mercados ${ }^{10}$.

Além disso, mesmo na hipótese remota de que todos os instrumentos tarifários e não-tarifários atualmente usados pelos EUA fossem abandonados, a opção pela ALCA tende a nos impor uma especialização ainda mais regressiva do que a verificada nos primeiros anos de abertura comercial das gestões Collor/Cardoso, o que nos conduziria à vocação pouco alvissareira de fornecedores de matérias primas. Segundo estudos do próprio governo dos EUA, os produtos brasileiros que apresentariam maior aumento nas exportações com a ALCA seriam os grãos, couro, carne, sementes oleaginosas, aço e açúcar ${ }^{11}$.

É evidente que, se de um lado há interesse do Brasil em não se isolar dos seus principais parceiros comerciais, o aprofundamento ainda maior dessas relações de troca não pode ser feito nem de maneira desequilibrada que redunde em redução dos nossos já exíguos

\footnotetext{
9 TREVISAN, Cláudia. EUA prometem "negociar tudo" na Alca. Valor Econômico, São Paulo, 19 nov. 2002.

${ }^{10}$ CARVAlHO, Luciana. Estudos dão subsídios às negociações. Gazeta Mercantil, São Paulo, 17 out. 2002.

${ }^{11}$ HUBBARD, Glenn. Alca: oportunidade de crescimento. Valor Econômico, São Paulo, 1 nov. 2002.
} 
saldos comerciais e muito menos à custa de uma especialização regressiva da indústria brasileira em produtos pouco dinâmicos no mercado internacional, cuja competitividade está baseada fundamentalmente em custos.

De maneira geral, podemos classificar os produtos de exportação em duas grandes categorias, que em outro trabalho ${ }^{12}$ designei, mercadorias ricardianas e mercadorias inovativas. As primeiras são aquelas comercializadas com base em seus custos relativos de produção e as últimas são produzidas e exportadas pelo país onde a inovação ocorreu independentemente dos custos de produtos. Quem se especializa nas primeiras, deverá necessariamente concorrer em custos e quem concorre em custos concorre basicamente em salários, ou seja, tem que manter os salários achatados em termos relativos para competir no mercado internacional. Já os que se especializam em mercadorias inovativas exportam, não porque seus custos de produção sejam mais baixos, mas porque os produtos que produzem, pelo seu conteúdo inovador, desfrutam de um monopólio temporário no mercado internacional que lhes permite não só obter maiores lucros como também pagar salários relativamente mais elevados aos seus trabalhadores.

Caso, portanto, a ALCA implique numa divisão intra-regional de trabalho baseada em critérios de eficiência alocativa de fatores produtivos, que nos conduza a uma especialização no que chamamos acima de mercadorias ricardianas, a manutenção de saldos comerciais positivos estará sempre condicionada ao pagamento de baixos salários.
Do que foi acima colocado, parece-nos que a estratégia brasileira de negociações para a formação da ALCA deve estar centrada em dois objetivos principais, sem os quais a viabilização do acordo é impossível.

No terreno das trocas comerciais de bens e serviços é preciso que um eventual acordo garanta:

1 - Abertura efetiva do mercado agrícola norte-americano, com a eliminação de subsídios à produção e à exportação, que impedem a entrada dos produtos agrícolas brasileiros naquele mercado e concorrem deslealmente com os produtos brasileiros em terceiros mercados;

2 - Adoção de normas claras e em acordo com as regras estabelecidas pela Organização Mundial do Comércio na aplicação de medidas antidumping, as quais têm sido hoje o principal instrumento para barrar as exportações brasileiras de produtos manufaturados, particularmente do setor siderúrgico.

No que diz respeito aos demais aspectos em negociação nos demais grupos de negociação da ALCA, a questão principal é que nenhum acordo que venha a ser firmado pelo Brasil o impeça de aplicar efetivamente políticas industriais que visem a transição de sua produção de mercadorias de baixo valor agregado para produtos inovativos e mais dinâmicos no mercado internacional.

Sem que as condições acima estejam explicitamente garantidas num eventual acordo, a ALCA, sob todos os aspectos que se queira analisar, representará um retrocesso para o Brasil.

\section{REFERÊNCIAS BIBLIOGRÁFICAS}

ANTUNES, Cláudia. O que importa na Alca. Folha de S. Paulo. São Paulo, 22 jan. 2003.

BATISTA JR., Paulo Nogueira. Os EUA e a Alca. Folha de São Paulo, São Paulo, 20 fev. 2003.

BRASIL, Embaixada do Brasil em Washington, D.C. Barreiras aos produtos e serviços brasileiros. Outubro 2002.

CARVALHO, Luciana. Estudos dão subsídios às negociações. Gazeta Mercantil, São Paulo, 17 out. 2002.

CARVALHO, Marco Antônio de. O Brasil não pode ser província. Gazeta Mercantil, São Paulo, 7 mar. 2002.

HUBBARD, Glenn. Alca: oportunidade de crescimento. Valor Econômico, São Paulo, 1 nov. 2002.

${ }^{12}$ PAULINO, Luis Antonio. O Brasil no Leito de Procusto. 1998. Tese (Doutorado em Economia) - IE -UNICAMP, Campinas, 1998. 
PAULINO, Luis Antonio. O Brasil no leito de Procusto. 1998. Tese (Doutorado em Economia) - IE -UNICAMP, Campinas, 1998. RICUPERO, Rubens. Os Estados Unidos e o comércio mundial: protecionistas ou campeões do livre-comércio. Estudos Avançados 46. São Paulo: Instituto de Estudos Avançados da Universidade de São Paulo. 2002.

SANDENBERG, C. A. A globalização pára. Na vez dos pobres. O Estado de São Paulo, São Paulo, 17 fev. 2003.

SOTERO, Paulo. Alca não é anexação, afirma Zoellick. O Estado de São Paulo, 15/10/2002.

TREVISAN, Cláudia. EUA prometem "negociar tudo" na Alca. Valor Econômico, São Paulo, 19 nov. 2002.

VERÍSSIMO, Renata. País prepara lista comum para a Alca. O Estado de São Paulo, São Paulo, 23 jan. 2003. 